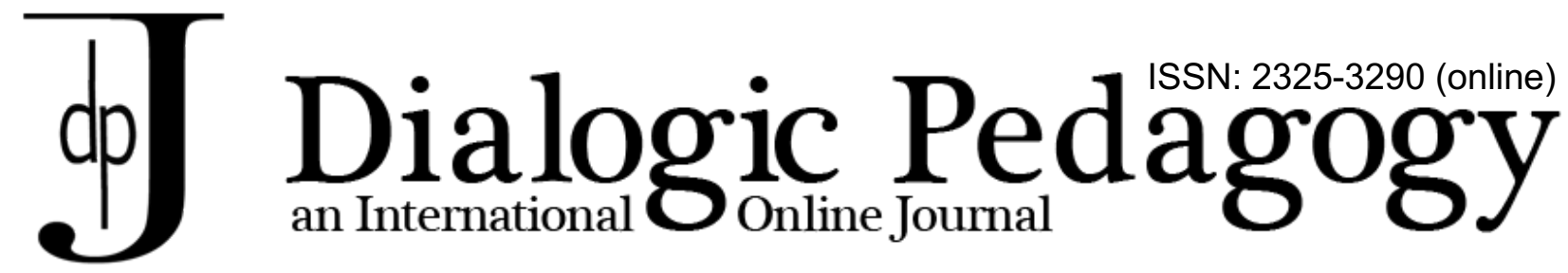

\title{
Supervision, Advisement and Dialogic Pedagogy: present day issues and provocations for the future
}

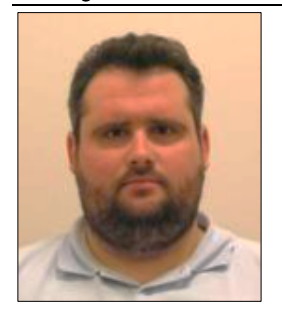

\author{
Mikhail Gradovski \\ University of Stavanger, Norway
}

\begin{abstract}
This article is a reflection on the Dialogic Pedagogy Journal (DPJ) Special Issue on Supervision and Advisement. Altogether five articles made it through a rigorous double-blind peer review process and crossed the finishing line to become a part of this special issue. Supervision and advisement are areas of education where Dialogic Pedagogy approach is a welcome guest as learning and teaching constructs that are used in these areas require various forms of dialogue. This special issue is a humble but a promising beginning for the special issues on supervision and advisement in this journal. All the studies included in this special issue are good examples of well-done scientific endeavors that can be used as illustrations of how a good piece of research should be executed and reported. However, the question remains if the means of analyses used in these studies are satisfactory enough so that we could understand to the fullest the complexities of the co-lived lives of the participants in supervisory and advisement relationships and co-learned knowledge that all the participants have gained.
\end{abstract}

Dr. Mikhail Gradovski is a professor of Social Pedagogy at the University of Stavanger, Norway. He was born in Minsk, Belarus. After graduation from the Norwegian University of Science and Technology in Trondheim as doctor rerum politicarum in 2008 with the thesis devoted to the Norwegian Dialogue Pedagogy, Gradovski has participated in both national and international research projects on doctoral supervision, professional supervision, use of dialogue in education, and mental skill development. Currently he is a main coordinator of the ISPAS project, an international EU Horizon 2020 project that focuses on the development of PhD candidates' skills. He has supervised both postgraduate, graduate and undergraduate students. As a teaching practitioner he is using a dialogical approach based on an understanding that both teacher and learner are partners with equal rights to make judgements on what is relevant, important and true.

\section{2बs}

\section{Introduction}

Australian Bakhtinians Jillian Hamilton and Sue Carson in their seminal article "Speaking of Supervision: A dialogic approach to building higher degree research supervision capacity in the creative arts" (Hamilton \& Carson, 2015), successfully argued that through dialogue we can gain insights into other ways of 'doing supervision', and of 'being a supervisor', develop a common language and shared understanding of what the field is, its practices, its language and definitions, and its impact. Inspired by the 
Hamilton and Carson (2015), the goal of the DPJ Special Issue on Supervision and Advisement is to present studies based on the dialogic pedagogy approach that provide new insights, contribute to the shared, deepened understanding of the practices and tacit knowledge in the field of supervision and advisement. Altogether five articles made it through a rigorous double-blind peer review process and crossed the finishing line to become part of this special issue. Supervision and advisement are areas of education where Dialogic Pedagogy approach is a welcome guest as learning and teaching constructs that are used in these areas require various forms of dialogue. This special issue is a humble but a promising beginning for the special issues on supervision and advisement in this journal. Bearing in mind an obvious demand for the dialogic pedagogical knowledge to develop these educational areas, there are good reasons to believe that there will be future special issues showcasing how new knowledge from the arsenal of Dialogic Pedagogy can help advances in both supervision and advisement. In this article I will first present the five studies included in this special issue and then I will describe the provocations for the future that the new knowledge from these studies espouses.

\section{DPJ special issue on supervision and advisement: present-day issues of supervision and advisement}

In Barbosa and Wang's study (2020) the authors use a Freirean perspective to find out what counts as good teaching according to the pre-service teachers who got engaged in a mini research-based practicum. The findings of the study show that the pre-service teachers believe that good teaching exists when there is an inclusive relationship building process in a classroom. Further, the good teaching should start with understanding the multiple roles a teacher could have. The authors discuss transformative effects of a dialogic problem-posing pedagogy, along with its challenges and coping methods. The focus of the Cubero, Bascón, \& Cubero-Pérez's study (2020) is on invocations (forms of the reflective practices) of the Spanish primary school teachers-to-be during their practicums. The authors view the practicum period as a dialogic construct for the explanation and interpretation of teaching practices and believe that it provides teachers-to-be with an opportunity for making their own meanings through dialogue and reflection. The authors define the profile of the invocations introduced in dialogic reflection as sources of legitimation of knowledge and identify the patterns in the sequence of the invocations' appearance. Analyzing the tutors' efforts to connect pedagogical principles with personal experiences during the practicum period, the authors discuss at the end the competencies and training that the students' tutors should need.

Vatne and Søndenå's study (2020) focuses on the supervision of the Norwegian pre-school teachers-to-be in connection to their bachelor theses. Drawing on the Bakhtinian dialogic perspective, the authors focus on how the supervision process contributes to changes in students' subjectivities. These changes are viewed as desirable and fruitful outcomes of the supervision process that pertain to the enhancing quality process. The findings of this study show that the students have either uncomplicated or complex subjectivity types. Further, the authors show that the priority is given to the voices that represent outer persuasive discourse and not students' inner persuasive discourses. These findings call for the changes in the process of supervision of such theses to encourage students to include their own lived experience in the theses and to allow room for emotions and creativity.

The study by Baxan, Pattison-Meek, \& Campbell (2020) explores learning activities of three teacher education graduate research methods courses aimed to support student learning beyond the mastering of research skills or techniques. Through the subtle but brilliant construction of the dialogue between their own narratives, these three Canadian teacher educators weave a tapestry of meaning making to illustrate how teachers-to-be can dialogically reflect on research-related topics with peers, bring questions forward for discussion in class and online, apply their emerging technical research skills through collective analysis of 


\section{Supervision, Advisement and Dialogic Pedagogy: present day issues and \\ provocations for the future}

Mikhail Gradovski

a given situation case, and grow collective knowledge together. In the unfolding of the narratives the authors show the constrains and limitations that appear on the road to teachers'-to-be recognition of the importance of research in their work.

Eriksen and Gradovski's study (2020) focuses on social work students' experiences of ethical challenges, including dilemmas, during their field placements. Drawing on dialogical approach and the results of the thematic analysis, the authors discuss what ethical dilemmas the students experience during their field practice, and what implications the handling of these ethical dilemmas can have for the organization of social work education. The authors argue that due to the fact that the authorial agency of any learner consists of personal attitudes, goals, values, knowledge, competences, and skills, it is important to organize field practice activities in a way that allows discussions in free and fearless environments and call for activities that create opportunities for the students to learn and unlearn knowledge and skills that are connected to their inner persuasive discourses.

So what other ways of 'doing supervision', and of 'being a supervisor' the studies in this special issue have suggested, and what new insights on the common language and shared understanding have these studies brought forth regarding what the field is, its practices, its language and definitions, and its impact? The authors of all the studies from this special issue argue for better recognition of the students or pupils' authorial agency in the processes of supervision and advisement. Barbosa and Wang (2020) argue for organizing both advisement and supervision basing them on the principles of Freirean dialogic problemposing pedagogy. Their main claim is that the use of this pedagogy will allow the students to have the agency to question the status quo of the curriculum, partnerships, and choices made by administrators.

Cubero, Bascón, \& Cubero-Pérez's study (2020) rightly consider students' practicums to be part of the professional socialization and argue for the use of dialogue to allow the students to reflect on the legitimacy of their claims and arguments. For this to happen it is necessary to make sure that the students' tutors are well prepared to assist students' reflections, i.e., the tutors need to learn. The necessity for more reflection and understanding of one's own agency is something Baxan, Pattison-Meek, \& Cambell (Baxan et al., 2020) also argue for. Using the dialogue as a means of communication in all its might and shining armour the authors show how one can "co-construct research knowledge through a dialogic approach, having Alexander's dialogic teaching principles (2018) as a start". This study shows the importance of becoming aware of one's own agentic position and how important it is for professionals to have opportunities to experience an interplay between one's own and others' outer and inner persuasive discourses for own professional and personal development.

The importance of these two discourses for the learning and teaching of the professional knowledge has also been highlighted in the study by Eriksen and Gradovski (2020). This study shows the importance of treating professionals-to-be as responsible adults and respect their points of view on what is right and just in regard to professional activities. Advocating for the right of professionals-to-be to have an opportunity to be have a room to voice personal views the study by Vatne and Søndenå (2020) shows that the issue of dialogical subjectivities of the professionals-to-be is not a purely educational issue but a political issue as well. To be dialogic in educational encounters in supervision and advisement means to be political!

\section{What provocations for the future the new knowledge from these studies espouses?}

As mentioned above Dialogic Pedagogy in all its brilliant forms and facets is a pedagogy of choice, in my view, when it comes to learning and teaching activities of supervision and advisement. The studies in this special issue provide us with new knowledge on how to organize learning activities so that all the 


\section{Supervision, Advisement and Dialogic Pedagogy: present day issues and \\ provocations for the future}

Mikhail Gradovski

participants experience developments of the meaning-making processes of various kinds and types. However, we still need to know more on what models and constructs allow the learners to use their own subjectivities to develop a sense of trust and respect for their own voice and opinions and encourage development of their own reflective practices and authorial agency. In this time of political unrest and social uncertainties we need more knowledge on what the use of dialogue contributes when it comes to practices of both students and teachers' resilience and resistance in educational situations.

All the studies included in this special issue are good examples of well-done scientific endeavors that can be used as illustrations of how a good piece of research should be executed and reported. However, the question remains if the means of analyses used in these studies are satisfactory enough so that we could understand to the fullest the complexities of the co-lived lives of participants of supervisory and advisement relationships and co-learned knowledge that all the participants have gained. The answer, in my view, is "no" as we direly need new developed methodologies and tools for analyses so that we could understand better the complexity of the processes in both supervision and advisement. It is important to acknowledge the present-day pioneers in the field of developing new methodologies and tools for analyses who are paving the way for the future dialogic pedagogy patriots. To such belong Eugene Matusov (Matusov, et al., 2019) and his methodological argumentation for the place and the application area of dialogic approach among the frameworks that belong to the qualitative approach, Rupert Wegerif and his Chiasm Methodology (Kershner, et al., 2020), and Jayne White's works on the use of video methods and the analyses of data collected with such methods (White, 2016, 2020). However, these are not enough. The most important provocation that this issue as a whole espouses is the need for more theoretical and methodological studies so that we can get new insights, contribute to the shared, deepened understanding of the practices and tacit knowledge in the field of supervision and advisement in the future.

\section{References}

Alexander, R. (2018). Developing dialogic teaching: Genesis, process, trial. Research Papers in Education, 33(5), 561-598. doi:10.1080/02671522.2018.1481140

Barbosa, P., \& Wang, W. (2020). Challenging the politics of education: intertwining dialogic pedagogy with a research-based practicum for first-year pre-service teachers. Dialogic Pedagogy: An International Online Journal, 8(2020), SA1 - SA25. doi:https://doi.org/10.5195/dpj.2020.306

Baxan, V., Pattison-Meek, J., \& Campbell, A. B. (2020). Dialogic pedagogy in graduate teacher education research advisement: A narrative account of three teacher educators. Dialogic Pedagogy: An International Online Journal, 8(2020), SA60 - SA84. doi:https://doi.org/10.5195/dpj.2020.308

Cubero, M., Bascon, M. J., \& Cubero-Perez, R. (2020). "My tutor doesn't say that": The legitimized voices in dialogic reflection on teaching practices. Dialogic Pedagogy: An International Online Journal, 8(2020), SA26 - SA44. doi:https://doi.org/10.5195/dpj.2020.311

Eriksen, H. L., \& Gradovski, M. (2020). Ethical dilemmas in field placements: The experiences of social work students in Norway and possible implications for social work education. Dialogic Pedagogy: An International Online Journal, 8(2020), SA85-SA111. doi:https://doi.org/10.5195/dpj.2020.322

Hamilton, J., \& Carson, S. (2015). Speaking of Supervision: A dialogic approach to building higher degree research supervision capacity in the creative arts. Educational Philosophy and Theory, 47(12), 1348-1366.

Matusov, E., Marjanovic-Shane, A., \& Gradovski, M. (2019). Dialogic Pedagogy and Polyphonic Research Art:: Palgrave Macmillan. 
Vatne, B., \& Søndenå, K. (2020). Subjectivity and change in process of supervision. Dialogic Pedagogy: An International Online Journal, 8(2020), SA45 - SA59. doi:https://doi.org/10.5195/dpj.2020.304

White, E. J. (2016). More than meets the "I": A polyphonic approach to video as dialogic meaning-making. Video Journal of Education and Pedagogy, 1(1), 6. doi:10.1186/s40990-016-0002-3

White, E. J. (Ed.) (2020). Seeing the World through Children's Eyes. Visual Methodologies and Approaches to Research in the Early Years. (Vol. 1): Brill Sense.

\section{(c) $)$ EY}

New articles in this journal are licensed under a Creative Commons Attribution 4.0 United States License.

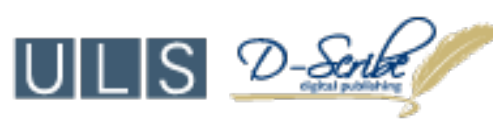

This journal is published by the University Library System, University of Pittsburgh as part of its D-Scribe Digital Publishing Program and is cosponsored by the University of Pittsburgh Press. 